\title{
The Application of Artificial Neural Network in the Transformer Oil Chromatographic Test
}

\author{
Wang Qinghao ${ }^{1}$, Li Weijun ${ }^{1}$, Pang Yanjun ${ }^{1}$, Liu Bo ${ }^{1}$, Wang Yi $^{1}$, Liu Zhitong ${ }^{2}$, Liu \\ Peng $^{1}$, Liu Xiao ${ }^{1}$, He Lishuai ${ }^{3}$, Tao Shuyi ${ }^{1}$ \\ ${ }^{1}$ Fushun Power Supply Company, Liaoning Electric Power Company Limited, State Grid, China \\ ${ }^{2}$ Shenyang Power Supply Company, Liaoning Electric Power Company Limited, State Grid, China \\ ${ }^{3}$ Maintenance Branch company, Liaoning Electric Power Company Limited, State Grid, China \\ sptlove51@126.com
}

Keywords: oil chromatogram; artificial neural network; fault diagnosis; sample library; transformer

\begin{abstract}
Power transformer is the core equipment in power system. Power transformer can be regarded as the structure of several nonlinear dynamic systems. In the fault diagnosis of transformer, there are still many shortcomings in the traditional experimental analysis methods. Artificial neural network technology, because of its irreplaceable advantages, is applied in transformer fault diagnosis field.In this paper, the principle and technical characteristics of artificial neural network and the process of establishing the sample library are introduced. The application of artificial neural network in the fault diagnosis of transformer is also illustrated.
\end{abstract}

\section{Introduction}

Artificial neural network (ANN) is a mathematical model based on biology. Artificial neural network has been widely used in various fields. Especially are in the intelligent system of nonlinear modeling and controller design, pattern classification and pattern recognition, associative memory and optimization calculation, etc. In power system, the artificial neural network technology has been widely applied to various aspects of power generation, power transmission, power supply etc.[1-3]

\section{Artificial Neural Network Theory and Technical Characteristics}

In the middle and late twentieth Century of 80s, artificial neural network (ANN) is a frontier research field which is developing rapidly all over the world. It is also a highly integrated interdisciplinary subject, involving many fields, such as neurophysiology, mathematical science, information science and computer science. Artificial neural network can simulate the structure of human brain and the process of human cognition. It is composed of a large number of artificial analog neurons and connected in a certain way. A single artificial neuron can realize the nonlinear relationship between input and output. Because they are connected and combined, artificial neural networks have complex nonlinear characteristics[4].

Artificial neural network (ANN) is an ideal pattern classifier, which has strong adaptive ability, self-learning ability, fault tolerance, and strong robustness. As shown in Figure 1, it is the structure of the most common multilayer feed forward neural network[5].

The network is composed of a layer, an input layer, an output layer and a plurality of intermediate layers (or hidden layers).At present, the method of error back propagation is the most widely used in the study of artificial neural network. At the end of the learning process, if the input value is given, such as the test sample, the artificial neural network (ANN) system can get the corresponding output value of forward calculation. 


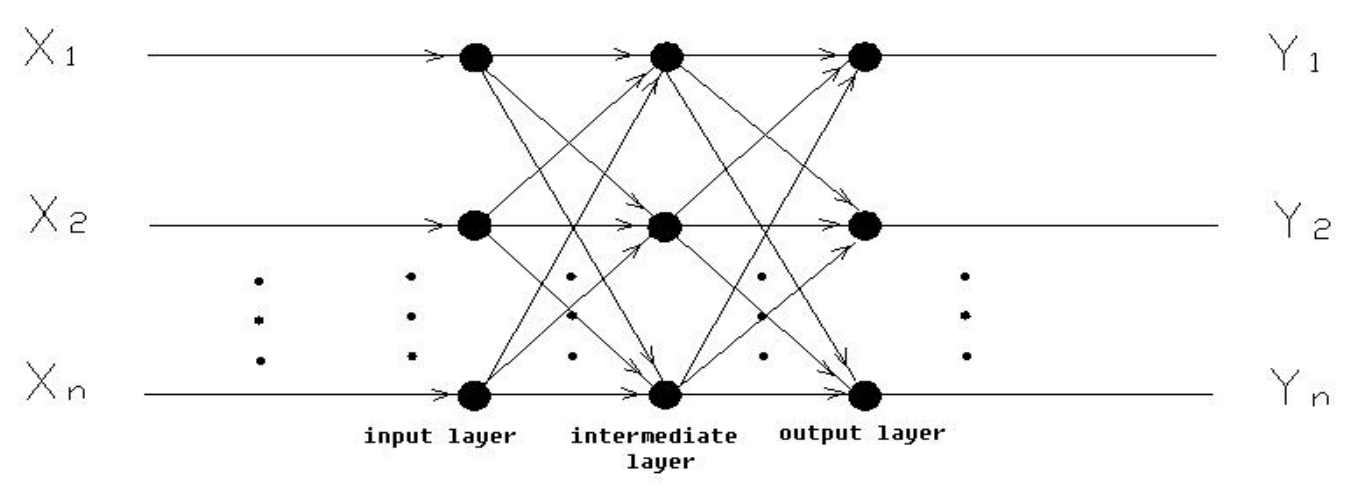

Fig. 1 Schematic diagram of multilayer feedforward neural network

\section{The Artificial Neural Network in Transformer Oil Chromatogram Monitoring Applications}

The artificial neural network is applied to the oil chromatogram monitoring experiment, so as to realize the fault diagnosis of the transformer. The diagnostic procedure is shown in Figure 2.

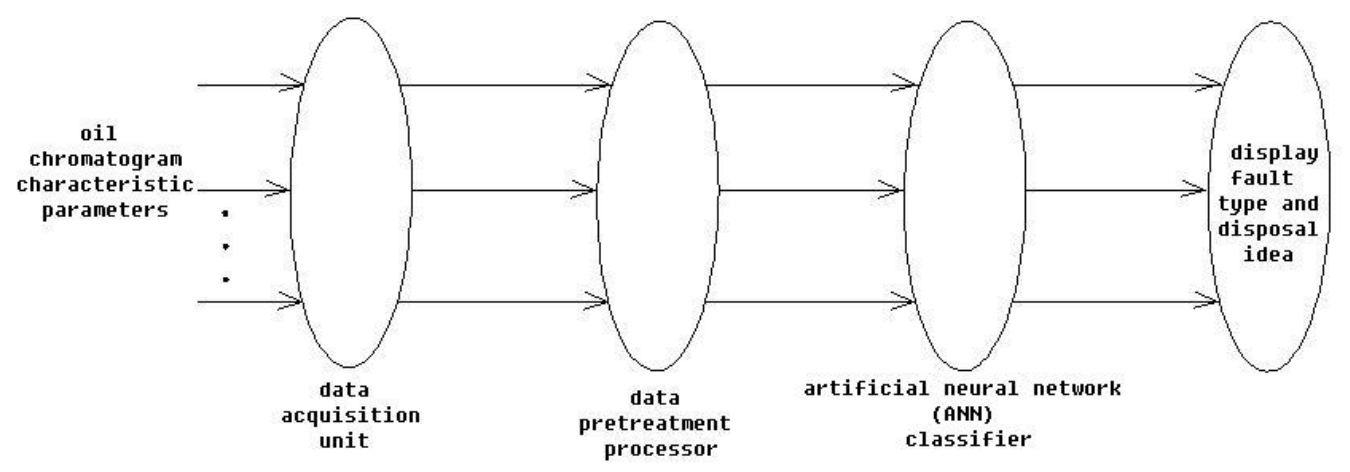

Fig. 2 Sketch map of artificial neural network fault diagnosis

(1) Data Acquisition Unit

With the help of different types of sensors, the data acquisition unit can be used to collect the environmental temperature, load current, characteristic gas $\left(\mathrm{CH}_{4} 、 \mathrm{C}_{2} \mathrm{H}_{6} 、 \mathrm{C}_{2} \mathrm{H}_{4} 、 \mathrm{C}_{2} \mathrm{H}_{2} 、 \mathrm{H}_{2} 、 \mathrm{CO}\right.$ 、 $\mathrm{CO}_{2}$ ) and characteristic parameters of the transformer.The collected data will be sent to the preprocessing unit for feature extraction.

(2) Data Pretreatment Processor

On the one hand, the input signal is analyzed and processed.On the other hand, the results of all the sampling and pre analysis are transformed into the input format which is suitable for the processing of the artificial neural network.

(3) Artificial Neural Network (ANN) Classifier

It takes the output of the pre processor as an input mode, which can be used to classify the input patterns by the nonlinear mapping of artificial neural network. The result of classification is directly related to the different fault states of transformer.The results will be displayed or sent to other related systems. The results will provide reference for maintenance personnel.When the transformer fault is found, the computer can show the type of transformer fault, and give the processing opinion.

\section{Principle of Transformer Fault Diagnosis}

At present, the artificial neural network is applied to transformer fault diagnosis, which mainly focus on the analysis of transformer oil chromatogram. When the transformer fault occurs, it will produce a set of characteristic gases and a corresponding set of three ratio codes.The fault type judgment is equivalent to the pattern recognition problem, so the artificial neural network can be 
used to diagnose the transformer fault.The basic principle of transformer fault diagnosis based on artificial neural network: transformer fault oil chromatographic digital information as the input of neural network, the neural network output means that the transformer fault diagnosis results.

Specific diagnostic principles: First, the neural network needs to be trained.The corresponding specific fault transformer oil chromatographic characteristic value as samples, establish a complete sample library.Secondly, all samples are used to train the neural network. The content of the sample library is stored in the form of network in the connection weights of the neural network. The connection between two nodes means that the weighted value of the signal, which is called weight.Generally speaking, the weight is equivalent to the artificial neural network memory means.Finally, through the neural network in view of the input amount of calculation, transformer fault diagnosis results can be got.

\section{Sample Library}

(1)Basis of Sample Selection

(1)The significance of selecting characteristic gases. When the transformer overheating fault or discharge failure, the resulting characteristic gases and their contents are different, as shown in Table 1.

Table 1 The gases of different fault types

\begin{tabular}{|c|c|c|}
\hline Fault type & Main components of gases & Minor component of gas \\
\hline Transformer oil overheating & $\mathrm{CH}_{4}, \mathrm{C}_{2} \mathrm{H}_{4}$ & $\mathrm{H}_{2}, \mathrm{C}_{2} \mathrm{H}_{6}$ \\
\hline $\begin{array}{c}\text { The overheating of transformer oil and } \\
\text { paper }\end{array}$ & $\mathrm{CH}_{4}, \mathrm{C}_{2} \mathrm{H}_{4}, \mathrm{CO}, \mathrm{CO}_{2}$ & $\mathrm{H}_{2}, \mathrm{C}_{2} \mathrm{H}_{6}$ \\
\hline $\begin{array}{c}\text { The partial discharge of transformer oil } \\
\text { paper insulation }\end{array}$ & $\mathrm{H}_{2}, \mathrm{CH}_{4}, \mathrm{CO}$ & $\mathrm{C}_{2} \mathrm{H}_{2}, \mathrm{C}_{2} \mathrm{H}_{4}, \mathrm{CO}_{2}$ \\
\hline $\begin{array}{c}\text { Spark discharge in transformer oil } \\
\text { Transformer oil electric arc }\end{array}$ & $\mathrm{H}_{2}, \mathrm{C}_{2} \mathrm{H}_{2}$ \\
\hline The arc of transformer oil and paper & $\mathrm{H}_{2}, \mathrm{C}_{2} \mathrm{H}_{2}$ & $\mathrm{CH}_{4}, \mathrm{C}_{2} \mathrm{H}_{4}, \mathrm{C}_{2} \mathrm{H}_{6}, \mathrm{CO}, \mathrm{CO}_{2}$ \\
\hline
\end{tabular}

(2) Three ratio coding method. Three ratio coding method is a method to judge the inner character of transformer. In the 5 kinds of characteristic gases, the characteristic gas with similar solubility and diffusion coefficient is used to form the three pair ratio. The 5 characteristic gases are $\mathrm{CH}_{4} 、 \mathrm{C}_{2} \mathrm{H}_{6} 、 \mathrm{C}_{2} \mathrm{H}_{4} 、 \mathrm{C}_{2} \mathrm{H}_{2} 、 \mathrm{H}_{2}$. The three ratio coding method, there are different gas ratio ranges and corresponding coding representation methods. The encoding rules are shown in table 2.

Table 2 The encoding rules

\begin{tabular}{|c|c|c|c|}
\hline \multirow{2}{*}{ The range of gas ratio } & \multicolumn{3}{|c|}{ The ratio range encoding } \\
\cline { 2 - 4 } & $\mathrm{C}_{2} \mathrm{H}_{2} / \mathrm{C}_{2} \mathrm{H}_{4}$ & $\mathrm{CH}_{4} / \mathrm{H}_{2}$ & $\mathrm{C}_{2} \mathrm{H}_{6} / \mathrm{C}_{2} \mathrm{H}_{4}$ \\
\hline$<0.1$ & 0 & 1 & 0 \\
\hline$\geqslant 0.1 \sim<3$ & 1 & 0 & 0 \\
\hline$\geqslant 1 \sim<3$ & 1 & 2 & 1 \\
\hline$\geqslant 3$ & 2 & 2 & 2 \\
\hline
\end{tabular}

Three ratio encoding corresponding relationship with the nature of transformer faults are shown in table 3 below. 
Table 3 The judgment method of fault character

\begin{tabular}{|c|c|c|c|c|}
\hline \multicolumn{3}{|c|}{ Coding combination } & \multirow{2}{*}{ Fault property judgment } & \multirow{2}{*}{ Fault example } \\
\hline $\mathrm{C}_{2} \mathrm{H}_{2} / \mathrm{C}_{2} \mathrm{H}_{4}$ & $\mathrm{CH}_{4} / \mathrm{H}_{2}$ & $\mathrm{C}_{2} \mathrm{H}_{6} / \mathrm{C}_{2} \mathrm{H}_{4}$ & & \\
\hline \multirow{5}{*}{0} & 0 & 1 & $\begin{array}{c}\text { Low temperature } \\
\text { superheating (Below } 150 \\
\text { DEG C ) }\end{array}$ & $\begin{array}{c}\mathrm{CO}, \mathrm{CO}_{2} \text { gas content and } \\
\mathrm{CO}_{2} / \mathrm{CO} \text { value need to be } \\
\text { noted. } \\
\text { Insulated conductor } \\
\text { overheating. }\end{array}$ \\
\hline & 2 & 0 & $\begin{array}{c}\text { Low temperature } \\
\text { superheating }\left(150^{\circ} \mathrm{C} \sim\right. \\
\left.300^{\circ} \mathrm{C}\right)\end{array}$ & \multirow{3}{*}{$\begin{array}{c}\text { Tap-changer poor contact. } \\
\text { Wire clip bolt looseness. Bad } \\
\text { welding joint. } \\
\text { Copper overheating caused by } \\
\text { eddy current. Core magnetic } \\
\text { flux leakage. } \\
\text { Local short circuit. Defective } \\
\text { insulation between the layers. } \\
\text { Transformer iron core } \\
\text { multipoint earthing. } \\
\text { And other aspects. }\end{array}$} \\
\hline & 2 & 1 & $\begin{array}{l}\text { Medium temperature } \\
\text { superheating }\left(300^{\circ} \mathrm{C} \sim\right. \\
\left.700^{\circ} \mathrm{C}\right)\end{array}$ & \\
\hline & $0,1,2$ & 2 & $\begin{array}{c}\text { High temperature } \\
\text { superheating (Above } 700 \\
\text { DEG C ) }\end{array}$ & \\
\hline & 1 & 0 & Partial discharge & $\begin{array}{l}\text { Due to high humidity, high } \\
\text { gas content. } \\
\text { Low energy density partial } \\
\text { discharge in transformer oil. }\end{array}$ \\
\hline \multirow[b]{2}{*}{2} & 0,1 & $0,1,2$ & Low-energy discharge & \multirow{2}{*}{$\begin{array}{l}\text { Continuous spark discharge } \\
\text { between the lead wire and the } \\
\text { non fixed part. } \\
\text { Tap-changer lead wire and oil } \\
\text { gap flashover. } \\
\text { Spark discharge in } \\
\text { transformer oil between } \\
\text { different potentials. } \\
\text { Spark discharge between } \\
\text { suspended potentials. }\end{array}$} \\
\hline & 2 & $0,1,2$ & $\begin{array}{c}\text { Low -energy discharge and } \\
\text { overheating }\end{array}$ & \\
\hline \multirow[b]{2}{*}{1} & 0,1 & $0,1,2$ & Arc discharge & \multirow{2}{*}{$\begin{array}{l}\text { Winding turn-to-turn, short } \\
\text { circuit between the layers. } \\
\text { Interphase flashover. } \\
\text { Oil gap flashover between } \\
\text { tap-changer leads. } \\
\text { Discharge between lead wire } \\
\text { and shell. } \\
\text { Coil fusing. } \\
\text { Tap-changer arcing. } \\
\text { Loop current arc. } \\
\text { Discharge of lead wire to } \\
\text { other ground objects. } \\
\text { And other aspects. }\end{array}$} \\
\hline & 2 & $0,1,2$ & $\begin{array}{l}\text { Arc discharge and } \\
\text { overheating }\end{array}$ & \\
\hline
\end{tabular}

(2) Establishment of Sample Library

The contents of the artificial neural network sample library include: the characteristic gas, the judgment standard, the operating parameter, the three ratio coding combination and the evaluation conclusion.

Characteristic gas: $\mathrm{CH}_{4} 、 \mathrm{C}_{2} \mathrm{H}_{6} 、 \mathrm{C}_{2} \mathrm{H}_{4} 、 \mathrm{C}_{2} \mathrm{H}_{2} 、 \mathrm{H}_{2} 、 \mathrm{CO} 、 \mathrm{CO}_{2}, \mathrm{C}_{1}+\mathrm{C}_{2}=\left(\mathrm{CH}_{4} 、 \mathrm{C}_{2} \mathrm{H}_{6}\right.$ 、 $\left.\mathrm{C}_{2} \mathrm{H}_{4} 、 \mathrm{C}_{2} \mathrm{H}_{2}\right)$;

Judging standard : $\mathrm{C}_{1}+\mathrm{C}_{2} \leq 150 \mu \mathrm{L} / \mathrm{L}$ （ the notice value ） $; \mathrm{H}_{2} \leq 150 \mu \mathrm{L} / \mathrm{L}$ （ the notice value ) $; \mathrm{C}_{2} \mathrm{H}_{2} \leq 5 \mu \mathrm{L} / \mathrm{L}$ (the notice value, $220 \mathrm{kV}$ and below voltage grade transformer ) $; \mathrm{C}_{2} \mathrm{H}_{2} \leq 1 \mu \mathrm{L} / \mathrm{L}$ 
(the notice value, $330 \mathrm{kV}$ and above voltage grade transformers);Absolute gas production rate $\leq 12$ $\mathrm{L} / \mathrm{d}$ (the notice value, Diaphragm type) ;Absolute gas production rate $\leq 6 \mathrm{~L} / \mathrm{d}$ (the notice value, Open type ）;Relative gas production rate $\leq 10 \mathrm{~L} /$ month（the notice value ）;

Operating parameters: ambient temperature, top oil temperature, load current, rated current, vibration sound;

Three ratio coding for all combinations: All three ratio coding combinations and the failure characteristics are corresponding to each encoding.

Evaluation conclusion: Class i, transformers can continue to run. Class ii, Transformer anomalies, need to be observed. Class iii, Transformer should be stopped as soon as possible. Class IV, transformer immediately stop running.

\section{Fault Case Analysis}

The transformer was Shenyang transformer factory products. In 1985, Chaoyang power plants with thick insulation copper coils and replace the original thin insulation and aluminum wire circle. During the period of running, the transformer once happened 2 times of failure. Thunderstorm on August 14, 2016, Fushun area, $220 \mathrm{kV}$ Gongnong substation, the two main transformer uses the parallel run, load is $41000 \mathrm{kw}$. At 16:50, the artificial neural network diagnosis system sends out alarm signal, and shows that the fault type is "high energy discharge fault". At the same time, it is concluded that the transformer should be stopped as soon as possible. Artificial neural network diagnosis technology is a new project, which has just been developed, although it has attracted the attention of the relevant departments, but the correctness of the research needs to be verified.

17:40, 2\# main transformer digital display prompt, pressure relief valve action. Operator immediately report scheduling. At the same time, the inspection was carried out immediately for No. 2 main transformer appearance, oil temperature and noise, found no abnormalities. In the mash gas collect chamber, mash gas content accounted for about half of the gas collection room space. The maintenance personnel immediately take samples of gas and oil samples for analysis. In August 15, 2016, the transformer winding deformation, DC resistance, insulation resistance, DC leakage and dielectric loss angle test results showed no abnormalities.

(1) Detection Result

The results of gas and oil sample analysis are shown in table 4.

Table 4 test data of oil chromatography $(\mu \mathrm{L} / \mathrm{L})$

\begin{tabular}{|c|c|c|c|c|c|c|c|c|}
\hline $\mathrm{CH}_{4}$ & $\mathrm{C}_{2} \mathrm{H}_{6}$ & $\mathrm{C}_{2} \mathrm{H}_{4}$ & $\mathrm{C}_{2} \mathrm{H}_{2}$ & $\mathrm{C}_{1}+\mathrm{C}_{2}$ & $\mathrm{H}_{2}$ & $\mathrm{CO}$ & $\mathrm{CO}_{2}$ & $\begin{array}{c}\text { Sampling } \\
\text { position }\end{array}$ \\
\hline 3017.61 & 68.17 & 675.52 & 1478.87 & 5240.17 & 23580 & 10950 & 5677 & mashgas \\
\hline 163.94 & 53.39 & 251.01 & 298.30 & 766.70 & 596 & 1273 & 7817 & $\begin{array}{c}\text { Transformer } \\
\text { oil sample 1\# }\end{array}$ \\
\hline 155.87 & 52.79 & 254.25 & 307.23 & 770.13 & 544 & 1149 & 7547 & $\begin{array}{c}\text { Transformer } \\
\text { oil sample 2\# }\end{array}$ \\
\hline
\end{tabular}

Transformer oil test data show that hydrogen gas, acetylene, total hydrocarbon content exceeds bid badly. The test data of the characteristic gas show that the acetylene content is high, the acetylene is the main component of the total hydrocarbon, and the hydrogen content is also high. According to the above two points, it can be identified as discharge fault.

Three ratio method:

$\mathrm{C}_{2} \mathrm{H}_{2} / \mathrm{C}_{2} \mathrm{H}_{4}=307 / 254=1.2$, Because the ratio is equal to 1.2 , and the number of between 1 to 3 , so the code is "1";

$\mathrm{CH}_{4} / \mathrm{H}_{2}=155 / 544=0.3$, Because the ratio is equal to 0.3 , and the number of between 0.1 to 1 , so the code is "0".; 
$\mathrm{C}_{2} \mathrm{H}_{4} / \mathrm{C}_{2} \mathrm{H}_{6}=254 / 53=4.8$, Because the ratio is equal to 4.8 , the ratio is greater than 3 , so the code is "2".

The three ratio coding combination is "1, 0,2 ", which is judged as high energy discharge fault (arc discharge). According to the mashgas analysis data, all kinds of fault gas concentration is much higher than the concentration of gas in transformer oil. The fault gas has not yet begun to dissolve in the transformer oil, it has entered the gas collection room. According to the above, there is a serious fault in the transformer. According to the gas content of $\mathrm{CO}$ and $\mathrm{CO}_{2}$, the fault has been related to the transformer insulation paperboard.

The above results and the artificial neural network diagnostic conclusions are basically identical. Staff immediately report the situation to the relevant departments of the company. The transformer is stopped and ready to be returned to the factory for inspection.

(2) Disassembly Inspection

August 20th, in the substation site, the transformer was checked. No abnormal situation of tap changer and lead wire. Between the A-phase and B-phase, B-phase insulation paperboard (the outer cardboard) there are traces of discharge. From the vertical point of view, the contact position between the middle winding pad and insulation paperboard, in the third section of the winding has 5 traces of electrical burns, in the fourth paragraph also has traces of electrical burns. B-phase high voltage insulation paperboard is opened, the innermost layer of paperboard has a large number of branch shape discharge burns. Details are shown in Figure 3 - 6.If the hidden trouble can not be found in time, it will cause the transformer winding inter turn short circuit accident.

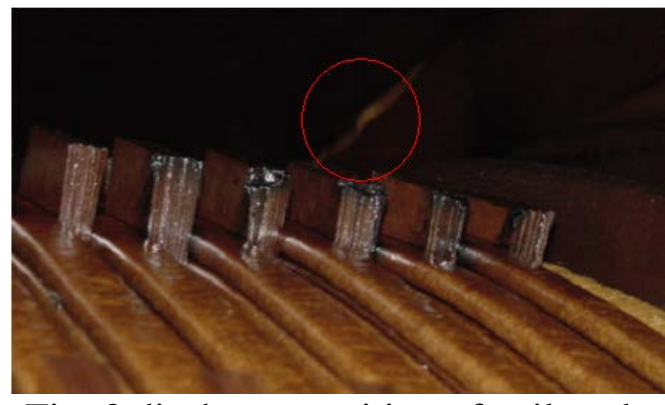

Fig. 3 discharge position of coil gasket

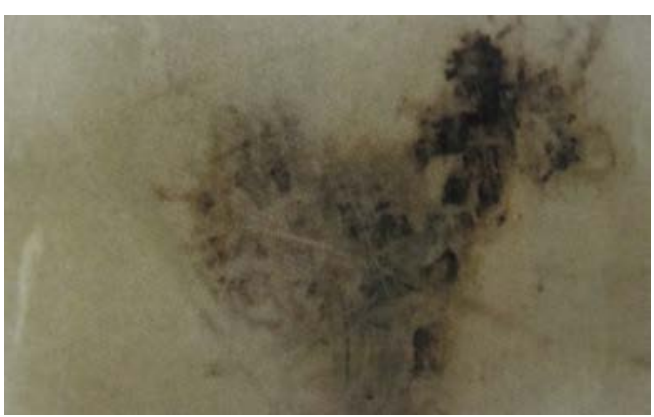

Fig. 5 discharge trace of inner insulation paperboard

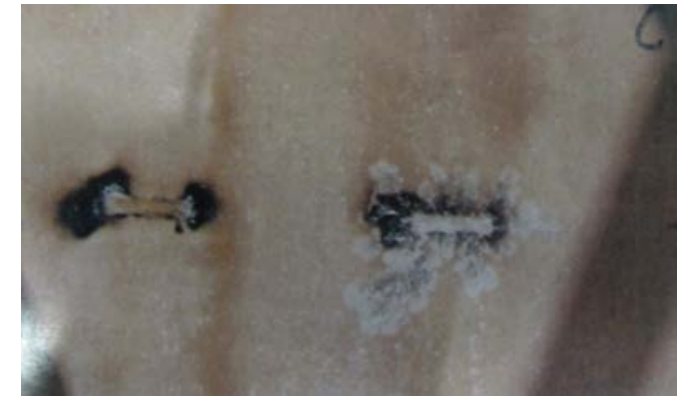

Fig. 4 discharge of the B- phase insulation board at the position close to the pad

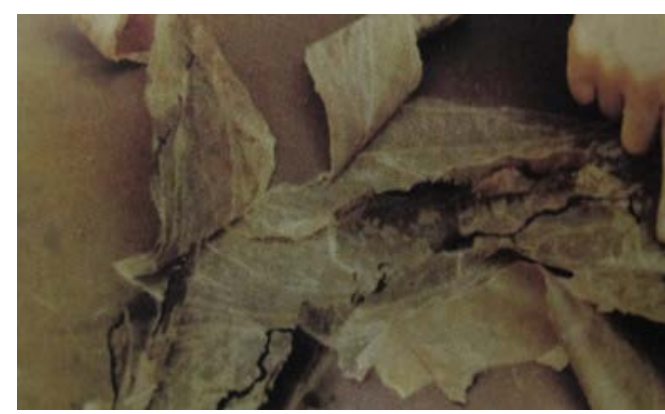

Fig. 6 large area dendritic discharge

\section{Conclusion}

The application example shows that the application of artificial neural network in the fault diagnosis of transformer is very timely and accurate.With the rapid development of modern science and technology, especially sensors, computer networks and databases, data analysis, etc..At the same time, there are mutual infiltration and cross between disciplines.Transformer fault diagnosis technology becomes more rapid and accurate. At present, there are some nonlinear problems similar to transformers, in power system.It is difficult to get a satisfactory solution by using traditional methods. As a kind of artificial intelligence, artificial neural network theory can solve this problem satisfactorily.Therefore, with the development of artificial neural network technology, more and more electrical equipment (such as circuit breaker, voltage transformer, current transformer, arrester, 
GIS, etc.) fault diagnosis problems can be solved.

\section{References}

[1] Qing Zhong , research on smart grid technology, Beijing: China Electric Power Press, 2011.05.

[2] Qiping Yang, Zhida Lan , transformer fault diagnosis based on artificial neural network [J], transformer 200,37 (3): 33-36.

[3] Dexiang Jia, Jing Han, neural network differential protection technology [J] electrician technology, 2003 (3): 11-12.

[4] Weigen Chen , application of wavelet packet energy spectrum entropy and neural network in fault diagnosis of circuit breaker [J], Journal of Chongqing University, 2008,31 (7).

[5] Xiaohui Xu , introduction to smart grid, Beijing: China Electric Power Press, 2009. 